\title{
DRG unterstützt „Pre Congress Course“ zum Rumänischen Röntgenkongress
}

Strahlenschutz und Fehlervermeidung in der Radiologie standen im Fokus des „Pre Congress Course“, der im Rahmen des Rumänischen Röntgenkongresses vom 20. bis 22. September 2018 mit Unterstützung durch die Deutsche Röntgengesellschaft e. V. (DRG) stattfand. Prof. Dr. Sönke Langner aus Rostock wurde für sein Engagement rund um den deutsch-rumänischen Austausch mit der Ehrenmitgliedschaft der Rumänischen Röntgengesellschaft ausgezeichnet.

Mit 120 Teilnehmenden war der Kurs ein großer Erfolg, wie auch die deutsch-rumänischen MR-Symposien, die bereits seit Jahren sehr gefragt sind. Seitens der DRG referierten PD Dr. Michael Walz von der Ärztlichen Stelle Hessen für Qualitätssicherung in der
Radiologie und Beisitzer der AG Informationstechnologie zum Thema Strahlenschutz, PD Dr. Florian Schwarz aus Augsburg zum Thema Strahlenschutz in der kardialen Bildgebung, PD Dr. Kolja Thierfelder aus der Radiologie der Uni Rostock zur Prostata-MRT, Dr. Paul-Christian Krüger von der Kinderradiologie der Uni Jena zur pädiatrischen Bildgebung, Bastian Klaan von der Radiologie der Uni Rostock zu MR-Arthrografie sowie Prof. Dr. Sönke Langner von der Radiologie der Uni Rostock zu Neuroradiologie und Strahlenschutz.

Für das kommende Jahr ist wieder ein MRSymposium in Rumänien geplant. Es soll vom 6. bis 7. Juni in Constanta stattfinden. Mehrere Referenten der DRG haben bereits zugesagt.

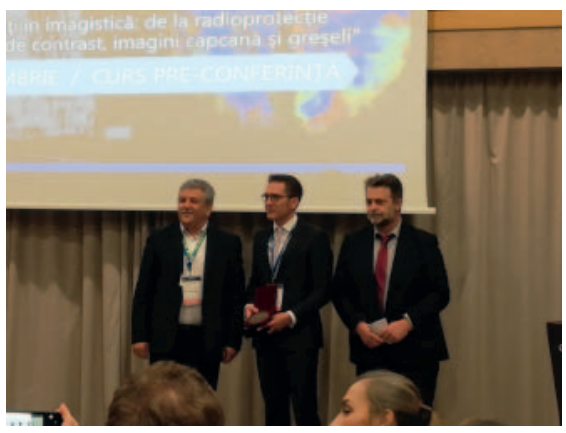

Prof. Dr. Sönke Langner (Mitte) wurde von Prof. Dr. Florin Birsasteanu (links), dem Präsidenten der Röntgengesellschaft, und Prof. Dr. Radu Baz (rechts), dem Kongresspräsidenten des Rumänischen Röntgenkongresses, mit der Ehrenmitgliedschaft ausgezeichnet. Foto: Deutsche Röntgengesellschaft 